\title{
PERBEDAAN HASIL TANGKAPAN BAGAN APUNG YANG MENGGUNAKAN LAMPU MERKURI DENGAN LAMPU LED
}

\section{COMPARISON OF CATCHES BOAT LIFTNET THE USE MERCURY LAMPS WITH LED LAMPS}

\author{
Muhammad Sulaiman ${ }^{1,2}$, Mulyono S. Baskoro², Am Azbas Taurusman², Sugeng Hari Wisudo², dan \\ Roza Yusfiandayani² \\ ${ }^{1}$ Dosen Politeknik Pertanian Negeri, Pangkep-Sulawesi Selatan \\ ${ }^{2}$ Dosen Fakultas Perikanan IImu Kelautan, Institut Pertanian Bogor, IPB \\ Teregistrasi I tanggal: 31 Oktober 2014; Diterima setelah perbaikan tanggal: 04 Juni 2015; \\ Disetujui terbit tanggal: 08 Juni 2015
}

\begin{abstract}
ABSTRAK
Teknik penangkapan ikan dengan alat tangkap bagan di Indonesia khususnya di Kabupaten Barru umumnya masih menggunakan lampu merkuri yang mana membutuhkan energi listrik yang cukup besar. Salah satu alternatif untuk mengurangi penggunaan energi listrik yang besar ini dapat digunakan jenis lampu hemat energi seperti lampu Light Emitting Diode (LED). Tujuan dari penelitian ini adalah untuk mengetahui perbedaan jenis ikan yang dominan tertangkap, komposisi jenis, dan berat ikan tertangkap antara bagan yang menggunakan lampu merkuri dengan lampu LED. Penelitian dilakukan di perairan Kabupaten Barru-Selat Makassar, Sulawesi Selatan. Lokasi pengamatan terletak pada posisi $4^{\circ} 22^{\prime} 48,7^{\prime \prime}-4^{\circ} 33^{\prime} 47,8$ "LS sampai dengan $119^{\circ} 25^{\prime} 05,0^{\prime \prime}$ 119³3'42,7"BT. Pengamatan lapang/uji coba penangkapan dilakukan pada periode OktoberNopember 2012 dan April-Mei 2013 (sebanyak 50 Trip penangkapan). Hasil penelitian menunjukkan bahwa komposisi hasil tangkapan bagan yang menggunakan lampu merkuri dan lampu LED didominasi oleh ikan teri hitam, teri putih, kembung lelaki, tembang, cumi-cumi, dan peperek, masing-masing sebanyak $90 \%$ dan $83 \%$. Dengan komposisi jenis hasil tangkapan yang demikian ini menunjukkan bahwa lampu LED dapat digunakan sebagai alat bantu penangkapan ikan karena mampu memikat jenis ikan target dan cenderung hasil tangkapannya sama dengan menggunakan lampu merkuri yang digunakan nelayan bagan. Terdapat perbedaan berat hasil tangkapan bagan yang menggunakan lampu merkuri dari pada yang menggunakan lampu LED, namun dari nilai hasil tangkapan tampak tidak berbeda. Berat jenis hasil tangkapan yang dominan tertangkap dengan lampu LED sebanyak $17,49 \mathrm{~kg} /$ watt sedangkan lampu merkuri sebanyak 4,89 kg/watt. Hasil ini menunjukkan bahwa bagan dengan lampu LED mendapatkan tangkapan lebih banyak dibandingkan dengan bagan lampu merkuri.
\end{abstract}

KATA KUNCI: Bagan, hasil tangkapan, perbedaan lampu merkuri, LED

\begin{abstract}
Fishing techniques with lift-net fishing gear in Indonesia especially in Barru Regency still use mercury lamp which require considerable electrical energy. Lamps that require low energy is an alternative that can be used to reduce the use of electrical energy. Lamps that require low energy, longevity, low heat radiation, and is resistant to shocks is a Light Emitting Diode (LED). The purpose of this research was to determine differences in the dominant fish species caught, species composition, and weight of fish caught between the lif-net fishing gear that uses a mercury lamp with LED lamp. The research was conducted in Barru waters regency, Makassar Strait, South Sulawesi on October-November 2012 and April-May 2013 (50 trips). Observation sites located on $4^{\circ} 22^{\prime} 48,7^{\prime \prime}-4^{\circ} 33^{\prime} 47,8^{\prime \prime}$ LS up to $119^{\circ} 25^{\prime} 05,0^{\prime \prime}$ $119^{\circ} 33^{\prime} 42,7^{\prime \prime} B T$. The composition of the catch between mercury lamps and LED lamps was dominated by black anchovy, white anchovy, indian mackerel, sardines, squid and golden ponyfish, respectively $90 \%$ and $83 \%$. These results indicate that the LED lights can be used as fishing tools because it is able to attract the target fish species and tend to catch higher than mercury lamps that commonly used. The difference in weight of the catch by using a mercury lamp was statistically better than the LED lights, but the value of the catch of the two types of lamps are not statistically different. Catches based upon the weight per electrical power used to indicate that the LED lights $(17.49 \mathrm{~kg} /$ watt) is better than the mercury lamp (4.89 kg / watt).
\end{abstract}

KEYWORDS: Lift net, catches, Comparison, LED lamp, mercury lamp 


\section{PENDAHULUAN}

Teknik penangkapan ikan dengan bantuan cahaya cahaya sebagai pengumpul ikan di Indonesia terutama di Kabupaten Barru umumnya masih menggunakan lampu merkuri yang membutuhkan energi yang besar khususnya bagi alat tangkap bagan. Peningkatan kompetensi usaha penangkapan mengakibatkan penambahan jumlah sumber pencahayaan dengan harapan dapat meningkatkan hasil tangkapan. Dengan peningkatan intensitas pencahayaan mengakibatkan konsumsi bahan bakar juga menjadi meningkat.

Penggunaan sumber pencahayaan saat ini maka permasalahan yang muncul adalah semakin banyak sumber penerangan yang digunakan berakibat semakin meningkatnya biaya operasional. Penggunaan bahan bakar khusus untuk sumber penerangan, nelayan liftnet (bagan petepete) di Kabupaten Barru menggunakan lampu merkuri 40 buah setara 250 watt sehingga menghabiskan 40 liter solar setiap setiap malamnya. Penggunaan bahan bakar ini diperkirakan menghabiskan $50 \%$ dari total penggunaan bahan bakar dalam satu kali trip.

Salah satu alternatif untuk mengurangi biaya operasional adalah dengan menggunakan lampu yang hemat energi. Jenis lampu hemat energi yang terus berkembang dan telah digunakan di berbagai bidang ilmu adalah lampu LED. Teknologi lampu LED dapat digunakan sebagai alternatif karena dapat menghemat energi, umur lampu lebih lama, radiasi panas rendah, dan tahan terhadap guncangan (Dharma et al., 2012). Penggunaan lampu LED semikonduktor telah diakui sebagai cara penting untuk penghematan energi dan perlindungan lingkungan (Hua \& Xing, 2013).

Penggunaan lampu merkuri dengan kapasitas daya listrik (watt) yang besar banyak digunakan oleh nelayan bagan di Sulawesi Selatan. Dari kondisi ini, perlu dicari alternatif untuk menggantikan lampu merkuri yang digunakan nelayan. Salah satu alternatif untuk mengurangi biaya operasional adalah dengan menggunakan lampu yang hemat energi dan ramah lingkungan seperti lampu LED. Teknologi lampu LED terus berkembang karena dapat menghemat energi, umur lampu lebih lama, radiasi panas rendah, dan tahan terhadap guncangan (Dharma et al., 2012; Hua \& Xing, 2013). Penelitian pemanfaatan lampu LED dalam bidang penangkapan ikan telah dilakukan oleh beberapa peneliti. Hasilnya menunjukkan bahwa penggunaan lampu LED dapat mengurangi konsumsi bahan bakar mencapai 55 persen (Okamoto et al., 2008), 47 persen (Sato et al., 2010), dan 24 persen (Matsushita et al., 2012). Penelitian tentang kemampuan tangkap dengan menggunakan lampu LED yang masih belum stabil adalah dalam mengumpulkan cumi-cumi pada catchable area (Yamashita et al., 2012; Sato et al., 2010), namun demikian Toeda et al. (2010) menyatakan bahwa lampu LED lebih stabil dan cepat dalam proses penangkapan dibandingkan dengan menggunakan lampu incandescent lamp (ICL) dan metal halid (MHL).

Penelitian tentang penerapan lampu LED untuk light fishing khususnya di bagan petepete di perairan tropis seperti Indonesia yang memiliki sumberdaya yang multi spesies belum banyak informasi sampai sekarang ini. Berdasarkan hal tersebut di atas, perlu dilakukan penelitian tentang bagaimana perbedaan hasil tangkapan bagan yang menggunakan lampu LED dan lampu merkuri. Tujuan dari penelitian ini adalah untuk mengetahui perbedaan jenis ikan yang dominan tertangkap, komposisi jenis, dan jumlah hasil tangkapan antara bagan yang menggunakan lampu merkuri dengan LED dengan harapan selanjutnya dapat digunakan oleh nelayan bagan sehingga mampu mengurangi biaya operasional penangkapan.

\section{BAHAN DAN METODE Tempat dan Waktu}

Pengoperasian bagan petepete dilaksanakan di Kabupaten Barru perairan Selat Makassar, Sulawesi Selatan. Percobaan penangkapan dilakukan dengan menggunakan dua buah bagan petepete dengan lokasi pengamatan terletak pada posisi $4^{\circ} 22^{\prime} 48,7^{\prime \prime}$ $4^{\circ} 33^{\prime} 47,8^{\prime \prime}$ LS sampai dengan $119^{\circ} 25^{\prime} 05,0^{\prime \prime}$ $119^{\circ} 33^{\prime} 42,7^{\prime \prime B T}$. Setiap loaksi penangkapan dicatat dengan menggunakan GPS (Garmin 76 CX). Satu unit bagan petepete dilengkapi dengan 20 unit lampu LED 80 watt, sedangkan bagan lainnya menggunakan 40 unit lampu merkuri 250 watt yang sekarang ini digunakan nelayan. Meskipun operasi penangkapan dilakukan pada 2 bagan yang berbeda milik nelayan, namun lokasinya berdekatan sehingga perbedaan karena faktor lingkungan dan sumberdaya ikan dapat dikurangi. Bagan petepete dioperasikan pada kedalaman 25-50 meter dengan jarak dari pantai Barru 3-11,5 mil laut (Gambar 1). Pengoperasian bagan dilakukan sebanyak 50 trip pada periode Oktober-November 2012 dan April-Mei 2013. 


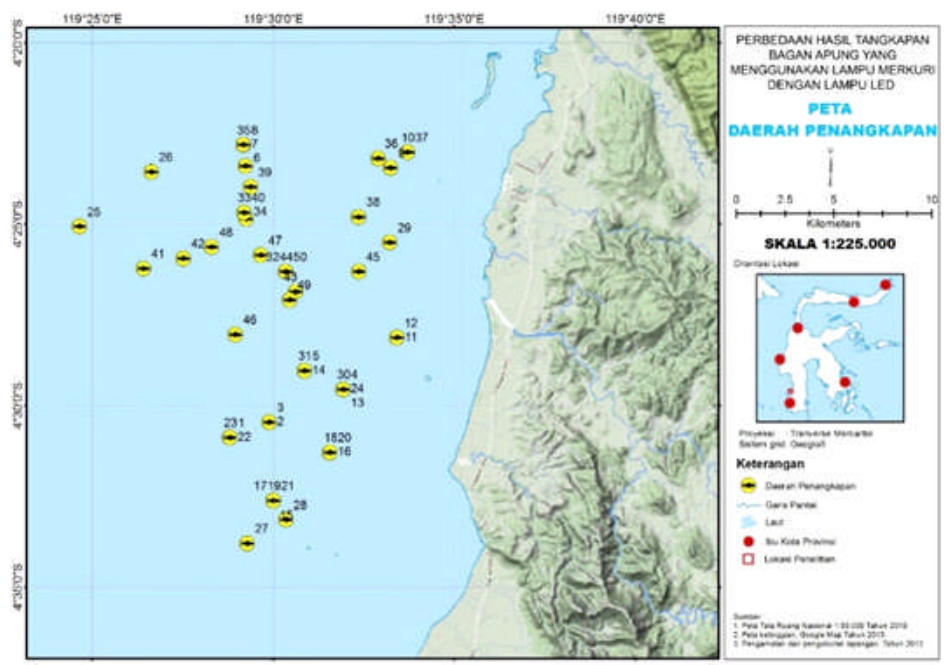

Gambar 1.Peta lokasi penangkapan bagan apung selama penelitian.

Figure 1. Map showing location of boat liftnet fishing during research.

\section{Metode}

Metode penelitian adalah percobaan penangkapan (experimental fishing). Pengumpulan data dilakukan dengan cara hasil tangkapan disortir berdasarkan jenis. Setiap jenis hasil tangkapan diambil satu basket untuk selanjutnya ditimbang berdasarkan waktu pengangkatan jaring (hauling) dengan ketelitian 95 persen. Total hasil tangkapan dihitung dengan menjumlahkan semua jenis ikan yang tertangkap dalam setiap hauling. Jenis ikan selanjutnya didokumentasikan dan diidentifikasi berdasarkan rujukan dari Fischer \& Whitehead (1974); Saanin (1984); Peristiwady (2006) juga dengan bantuan foto yang diunduh dari http//:fishbase.org. Hasil tangkapan selanjutnya dimasukkan ke dalam stryrofoam. Untuk menghambat kemunduran mutu, maka ikan di campur dengan es atau garam di dalam stryrofoam.

\section{Analisis Data}

Persentase komposisi jenis hasil tangkapan selama penelitian dan komposisi jenis berdasarkan menurut waktu pengamatan dihitung dengan menggunakan rumus:

$p=\frac{n_{1}}{N} \times 100 \%$

dimana: $p=$ persentase berat satu jenis ikan yang tertangkap; $\mathrm{n} 1$ = berat satu jenis ikan setiap kali sampling $(\mathrm{kg}) ; \mathrm{N}=$ berat total tangkapan setiap kali hauling $(\mathrm{kg})$
Uji beda t-test digunakan untuk menentukan apakah dua sampel yang tidak berhubungan memiliki nilai rata-rata yang berbeda dengan rumus sebagai berikut (Trihendradi, 2012):

$t_{\text {hitung }}=\frac{\left(\bar{x}_{1}-\bar{x}_{2}\right)-\left(\mu_{1}-\mu_{2}\right)}{\sqrt{\frac{\sigma_{1}^{2}}{n_{1}}+\frac{\sigma_{2}^{2}}{n_{2}}}}$

\section{Keterangan:}

$$
\begin{aligned}
\overline{\mathrm{X}} & =\text { rata-rata sampel } \\
\mu & =\text { nilai tengah umum hasil tangkapan } \\
\sigma & =\text { standar deviasi sampel } \\
\mathrm{n} & =\text { jumlah sampel }
\end{aligned}
$$

Analisis perbedaan hasil tangkapan antara bagan yang menggunakan lampu merkuri dan LED berdasarkan berat dengan daya listrik yang digunakan dilakukan dengan membuat grafik perbandingan dengan menggunakan software excel. Grafik perbandingan dibuat dengan sumbu $X$ adalah berat/ daya listrik ( $\mathrm{kg} /$ watt) setiap jenis hasil tangkapan lampu LED dan sumbu $Y$ adalah berat/daya listrik (kg/watt) setiap jenis hasil tangkapan lampu merkuri yang telah di bagi dengan jumlah watt lampu yang digunakan (LED-1600 watt dan merkuri-10.000 watt)

Diasumsikan dalam penelitian ini hanya intensitas cahaya yang dianggap berperan, dimana daerah penangkapan dianggap sama. Faktor oseanografi dianggap sama karena kedua bagan berada di lokasi perairan yang berdekatan dengan jarak kurang lebih satu mil. 


\section{HASIL DAN BAHASAN HASIL}

\section{Komposisi Jenis Hasil Tangkapan}

Jenis ikan yang tertangkap selama penelitian dengan alat tangkap bagan petepete baik yang menggunakan lampu merkuri maupun lampu LED umumnya adalah ikan pelagis kecil yang sifatnya bergerobol. Jenis ikan yang dominan tertangkap adalah teri hitam (Stolephorus insularis), teri putih (Stolephorus indicus), layang (Decapterus ruselli), kembung lelaki (Rastrelliger kanagurta), tembang (Sardinella fimbriata), bete-bete atau peperek (Leiognatus spp) dan cumi-cumi (loligo spp).

Kelompok ikan lainnya yang tertangkap bagan petepete adalah ikan berukuran kecil yang tidak teridentifikasi, layur (Lepturacanthus savala), barakuda (Sphyraena genie), talang-talang (Scomberoides lysan), selar (Megalaspis cordyla), beronang lingkis (Siganus canaliculatus), japuh (Dussumieria acuta), barakuda obtuse (Sphyraena obtusata), dan lolosi merah (Pterocaesio chrysozona). Kelompok ikan ini merupakan hasil tangkapan yang tidak dominan secara keseluruhan selama penelitian, walaupun pada suatu waktu hauling tertentu ada yang dominan tertangkap.

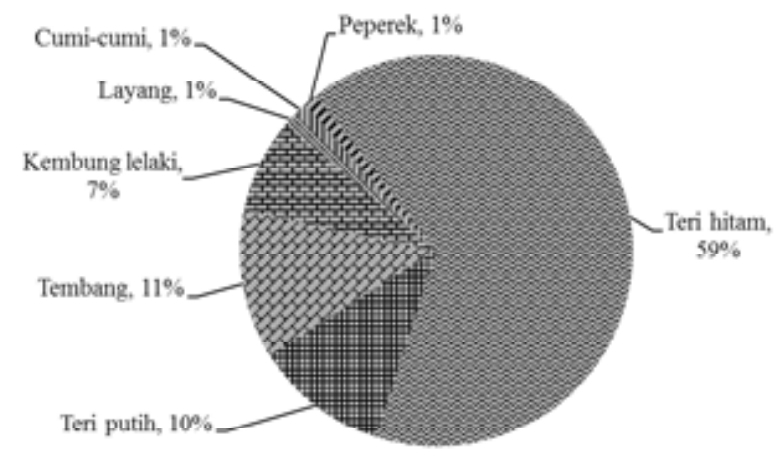

Gambar 2. Komposisi jenis hasil tangkapan bagan petepete yang menggunakan lampu merkuri selama penelitian.

Figure 2. Species composition of the catch bagan petepete that using mercury lamps during the research.

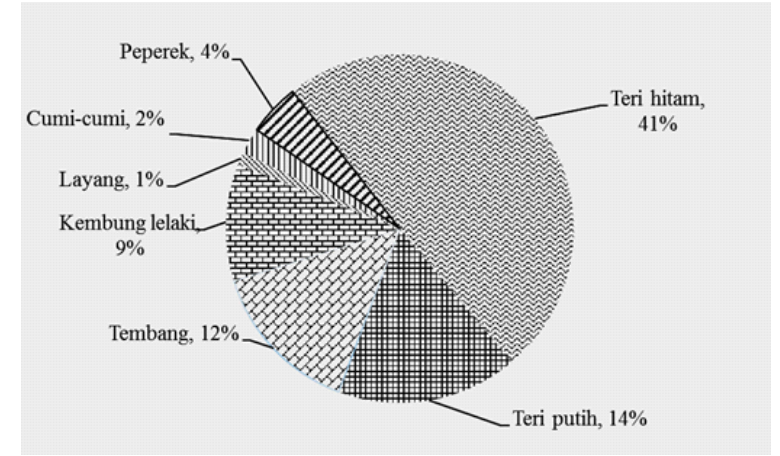

Gambar 3. Komposisi jenis hasil tangkapan bagan petepete yang menggunakan lampu LED selama penelitian. Figure 3. Species composition of the catch bagan petepete that using LED lamps during the research. 
Perbedaan Hasil Tangkapan Lampu Merkuri dan LED

Nilai analisis berat hasil tangkapan lampu merkuri dan LED 0,040 berpengaruh nyata pada taraf 0,05 , sedangkan nilai analisis harga hasil tangkapan lampu merkuri dan LED 0,68. Adanya perbedaan antara berat dan harga disebabkan adanya jenis hasil tangkapan dominan yang nilai jualnya berpengaruh terhadap berat hasil tangkapan (Tabel 1 dan Tabel 2).

Tabel 1. Uji Perbedaan berpasangan berat $(\mathrm{kg})$ hasil tangkapan antara lampu merkuri dengan LED Table 1. Paired sample $t$-Test of the catch weight $(\mathrm{kg})$ between mercury lamps with LED

95\% Confidence Interval

\begin{tabular}{|c|c|c|c|c|c|c|}
\hline \multirow{2}{*}{\multicolumn{2}{|c|}{ (I) Jenis_Lampu ( $\mathrm{J})$ Jenis_Lampu }} & \multirow{2}{*}{$\begin{array}{c}\text { Mean } \\
\text { Difference (I-J) }\end{array}$} & \multirow{2}{*}{$\begin{array}{l}\text { Std. } \\
\text { Error }\end{array}$} & \multirow[b]{2}{*}{ Sig. ${ }^{a}$} & \multicolumn{2}{|c|}{ for Difference ${ }^{a}$} \\
\hline & & & & & Lower Bound & $\begin{array}{l}\text { Upper } \\
\text { Bound }\end{array}$ \\
\hline D & Mercury &,$- 094^{*}$ & , 045 & , 040 &,- 183 &,- 004 \\
\hline Mercury & LED &, $094^{*}$ & ,045 & 040 & ,004 &, 183 \\
\hline
\end{tabular}

Dependent Variable: Berat_lkan

Based on estimated marginal means

*. The mean difference is significant at the .05 level.

Tabel 2. Perbedaan berpasangan harga (Rp) hasil tangkapan antara lampu merkuri dengan LED Table 2. Paired sample $t$-Test of the catch Value (IDR) between mercury lamps with LED

\begin{tabular}{|c|c|c|c|c|c|c|}
\hline \multirow[t]{2}{*}{ (I) Jenis_Lampu } & \multirow[t]{2}{*}{ (J) Jenis_Lampu } & \multirow{2}{*}{$\begin{array}{c}\text { Mean } \\
\text { Difference } \\
(\mathrm{I}-\mathrm{J})\end{array}$} & \multirow{2}{*}{$\begin{array}{l}\text { Std. } \\
\text { Error }\end{array}$} & \multirow[t]{2}{*}{ Sig. ${ }^{a}$} & \multicolumn{2}{|c|}{$\begin{array}{l}\text { 95\% Confidence Interval for } \\
\text { Difference }^{\mathrm{a}}\end{array}$} \\
\hline & & & & & Lower Bound & Upper \\
\hline LED & Mercury &,- 094 & ,051 & ,068 &,- 196 & ,007 \\
\hline Mercury & LED & 094 & 051 & ,068 &,- 007 & , 196 \\
\hline
\end{tabular}

Dependent Variable: Harga_lkan

Based on estimated marginal means

a. Adjustment for multiple comparisons: Least Significant Difference (equivalent to no adjustments).

Berat hasil tangkapan jenis ikan yang dominan tertangkap lampu LED $17,49 \mathrm{~kg} /$ watt sedangkan lampu merkuri $4,89 \mathrm{~kg} /$ watt. Berat $(\mathrm{kg} / \mathrm{watt})$ hasil tangkapan setiap jenis ikan yang dominan tertangkap

disampaikan dalam Tabel 3 dan Gambar 4, memperlihatkan bahwa hasil tangkapan lampu LED lebih banyak dibandingkan dengan hasil tangkapan lampu merkuri.

Tabel 3. Berat (kg/watt) jenis hasil tangkapan dominan selama penelitian

Table 3. Weight ( $\mathrm{kg} /$ watt) the dominant type of catches during the research

\begin{tabular}{|c|c|c|c|c|c|}
\hline \multirow[b]{2}{*}{$\begin{array}{l}\text { Nama ilmiah/ } \\
\text { Scientific } \\
\text { name }\end{array}$} & \multicolumn{2}{|c|}{ Jenis Ikan/Species composition } & \multirow[b]{2}{*}{$\begin{array}{l}\text { Nama lokal/ } \\
\text { Local name }\end{array}$} & \multicolumn{2}{|c|}{$\begin{array}{c}\text { Tangkapan/Catch } \\
\text { (kg/watt) }\end{array}$} \\
\hline & $\begin{array}{l}\text { Nama Inggris/ } \\
\text { English name }\end{array}$ & $\begin{array}{l}\text { Nama Indonesia/ } \\
\text { Indonesian name }\end{array}$ & & LED & Merkuri \\
\hline $\begin{array}{l}\text { Stolephorus } \\
\text { insularis }\end{array}$ & $\begin{array}{l}\text { Ardenberg's } \\
\text { anchovy }\end{array}$ & Teri hitam & Lure bolong & 8,71 & 3,21 \\
\hline $\begin{array}{l}\text { Stolephorus } \\
\text { indicus }\end{array}$ & Indian anchovy & Teri putih & Lure pute & 2,90 & 0,56 \\
\hline Loligo spp & Squid & Cumi-cumi & Cumi & 0,40 & 0,07 \\
\hline $\begin{array}{l}\text { Sardinella } \\
\text { fimbriata }\end{array}$ & $\begin{array}{l}\text { Fringescale } \\
\text { sardinella }\end{array}$ & Tembang & Tembang & 2,55 & 0,57 \\
\hline $\begin{array}{l}\text { Decapterus } \\
\text { russelli }\end{array}$ & Indian scad & Layang & Lajang & 0,24 & 0,04 \\
\hline $\begin{array}{l}\text { Rastrelliger } \\
\text { canagurta }\end{array}$ & Indian mackerel & Kembung lelaki & Banyara & 1,89 & 0,36 \\
\hline $\begin{array}{l}\text { Leiognathus } \\
\text { aureus }\end{array}$ & Golden ponyfish & Peperek & Bete-bete & 0,80 & 0.08 \\
\hline Jumlah/Total & & & & 17,49 & 4,89 \\
\hline
\end{tabular}




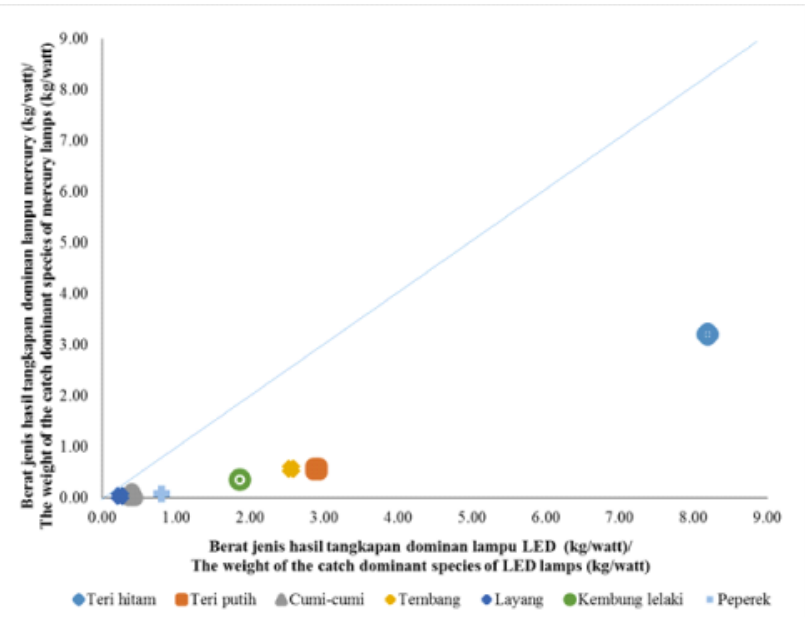

Gambar 4. Distribusi berat (kg/watt) jenis hasil tangkapan yang dominan selama penelitian antara lampu LED dan merkuri.

Figure 4. Weight distribution ( $\mathrm{kg} /$ watt) is the dominant type of catches during the research betweenLED and mercury lamps.

Distribusi berdasarkan berat dan daya listrik yang digunakan dari jenis ikan yang dominan selama penelitian dapat dilihat pada Gambar 4 yang menunjukkan bahwa semua jenis hasil tangkapan yang dominan berada di bawah garis linear. Hal ini berarti bahwa semua jenis tangkapan berdasarkan berat dan daya listrik yang digunakan dengan lampu LED mempunyai nilai yang lebih besar dibandingkan dengan lampu merkuri.

\section{BAHASAN}

Hasil tangkapan bagan petepete yang menggunakan lampu merkuri maupun LED didominasi oleh ikan teri hitam, teri putih tembang kembung lelaki, tembang, cumi-cumi dan peperek. Jenis ikan lainnya adalah ikan predator dan spesies yang bukan menjadi tujuan utama penangkapan. Komposisi hasil tangkapan yang dominan sebagai ikan target sebesar $90 \%$ dengan menggunakan lampu, sementara dengan lampu LED diperoleh $83 \%$ ikanikan dominan. Banyaknya jenis ikan yang tertangkap di daerah pencahayaan karena pada daerah tersebut terjadi rantai makan memakan yang juga merupakan perairan tropis terdapat beraneka ragam spesies. Keanekaragaman hasil tangkapan pada perikanan bagan juga sesuai dengan apa yang dikatakan Sudirman (2003), bahwa 94\% hasil tangkapan bagan rambo didomonasi oleh ikan teri, layang, kembung, selar, tembang, japuh dan cumi-cumi. Demikian juga Sulaiman (2006) melaporkan hasil penelitian bahwa $81 \%$ hasil tangkapan bagan rambo adalah jenis ikan kembung, teri, layang, tembang dan cumi-cumi, hal ini dikarenakan konsekuensi daerah tropis dimana terdapat spesies yang sangat beragam.
Komposisi jenis ikan yang tertangkap dengan menggunakan lampu merkuri maupun lampu LED menunjukkan spesies yang sama, namun berbeda dalam jumlah. Komposisi hasil tangkapan ini menunjukkan bahwa lampu LED dapat digunakan sebagai alat bantu penangkapan alternatif yang baik karena hasil tangkapannya menunjukkan hasil yang sama bahkan lebih baik dari jumlah ikan yang tertangkap dari lampu merkuri yang sekarang ini digunakan nelayan.

Perbedaan berat hasil tangkapan lampu merkuri lebih besar atau berpengaruh nyata secara statistik (t d" 0,05) di bandingkan lampu LED, sedangkan perbandingan nilai hasil tangkapan antara lampu merkuri dan LED tidak berbeda nyata atau relatif sama. Hal ini di sebabkan lampu LED menangkap ikan teri putih lebih banyak dari lampu merkuri. Walapun hasil tangkapan lampu merkuri yang lebih besar dibandingkan lampu LED, namun nilai jual hasil tangkapan lampu LED tidak berbeda secara statistik. Hal ini dapat terjadi karena lampu LED lebih banyak menangkap ikan teri putih yang lebih ekonomis atau mempunyai harga jual yang tinggi sehingga perbandingan nilai antara lampu merkuri dan LED secara statistik tidak berbeda nyata. Hal ini sesuai pendapat Okamoto et al. (2008) bahwa rata-rata hasil tangkapan ikan sauri pasifik dengan menggunakan lampu LED hampir sama dengan lampu konvensional.

Hasil penelitian juga menunjukkan bahwa lampu LED lebih ekonomis dibandingkan lampu merkuri, hal ini dapat dilihat dari besarnya watt sumber cahaya yang digunakan dalam melakukan operasi penangkapan ikan. Dimana lampu merkuri 
menggunakan 10.000 watt untuk menghasilkan 4,89 $\mathrm{kg} /$ watt, sedangkan lampu LED hanya menggunakan 1.600 watt untuk menghasilkan $17,49 \mathrm{~kg} /$ watt hasil tangkapan. Adanya perbedaan perbandingan hasil tangkapan dikarenakan pencahayaan lampu LED yang lebih fokus dapat masuk ke perairan yang lebih dalam dan jauh sehingga dapat menarik ikan yang jaraknya jauh untuk berkumpul di sekitar pencahayaan.

Baik lampu merkuri dan lampu LED yang digunakan sebagai alat bantu mengumpulkan ikan ternyata tidak menangkap jenis ikan yang dilarang atau dilindungi. Oleh karena penggunaan lampu LED lebih efiesien dan ramah lingkungan sebagai alat bantu penangkapan ikan LED (Dharma et al., 2012; Hua \& Xing, 2013), maka dapat direkomendasikan agar lampu LED dapat digunakan sebagai pengganti lampu merkuri yang lebih boros dan umur lampu yang singkat.

\section{KESIMPULAN}

Jenis ikan yang dominan tertangkap baik menggunakan lampu merkuri maupun LED adalah teri hitam (Stolephorus insularis), teri putih (Stolephorus indicus), layang (Decapterus ruselli), kembung lelaki (Rastrelliger canagurta), tembang (Sardinella fimbriata), bete-bete atau peperek (Leiognatus aureus) dan cumi-cumi (loligo sp).

Dominasi hasil tangkapan bagan petepete dengan lampu merkuri adalah $90 \%$ dan sedangkan dengan lampu LED 83\% yang terdiri ikan teri hitam, teri putih tembang, kembung lelaki, cumi-cumi dan peperek.

Perbedaan berat $(\mathrm{kg})$ hasil tangkapan lampu merkuri secara statistik lebih baik dibandingkan dengan lampu LED, namun perbedaan nilai (Rp) hasil tangkapan relatif sama atau tidak berbeda nyata. Lampu LED lebih baik daripada lampu merkuri dilihat dari perbandingan berat per daya listrik yang digunakan, dimana nilai berat hasil tangkapan per daya listrik lampu LED sebesar 17,334 kg/watt sedangkan lampu merkuri hanya $4,916 \mathrm{~kg} /$ watt.

\section{PERSANTUNAN}

Kami sangat berterima kasih kepada $\mathrm{H}$. Basri pemilik bagan petepete, nahkoda dan anak buah Kapal Daramuda untuk kerjasamanya selama penelitian. Penelitian ini sebagian dibiayai oleh Ditjen Dikti melalui bantuan beasiswa BPPS.

\section{DAFTAR PUSTAKA}

Dharma, C.S., F.D. Setiaji, \& D. Santoso. 2012. Pengatur Intensitas Lampu Philips Master Led Secara Nirkabel. J.Ilmiah.Elektroteknika. 11 (2). 141- 150 .

[DJPT-KKP] Direktorat Jenderal Perikanan TangkapKementrian Kelautan dan Perikanan. 2012. Statistik Perikanan Tangkap: Sistem Informasi dan Diseminasi Data Statiktik Kelautan dan Perikanan Kementrian Kelautan dan Perikanan 2010. Jakarta. Direktorat Jenderal Perikanan Tangkap Kementrian Kelautan dan Perikanan.

Fischer W, \& P.J.P. Whitehead. 1974. FAO Species Identification Guide for Fishery Purposes. Eastern Indian Ocean - Fishing Area 57 and Western Central Pacific - Fishing Area 71 Pacific. Volume 1,2,3. Bony: Families. Food and Agriculture Organization of the United Nations. Rome. 867 pp.

Gasperzs, V. 1991. Metode Perancangan Percobaan. Untuk IImu-ilmu Pertanian, IImu-ilmu Tenik dan Biologi. Armico Bandung. Bandung. 472 hal.

Hua L.T., \& J. Xing. 2013. Research on LED Fishing Light. Res.J.Applied.Sci.Eng and Tech. 5(16). 4138-4141.

Matsushita Y., T. Azuno, \& Y. Yamashita. 2012. Fuel reduction in coastal squid jigging boats equipped with various combinations of conventional metal halide lamps and low-energy LED panels. J.Fish.Res. 125-126: 14-19.

Okamoto T., K. Takahashi, H. Ohsawa, K. Fukuchi, K. Hosogane, S. Kobayashi, M. Moniwa, K. Sasa, H. Yoshino, H. Ishikawa, H.M. Makoto, K. Asakura, \& H. Ishii. 2008. Application of LEDS to Fishing Lights for Pacific Saury. J.Light \& Vis. Env. 32 (2). 38-42.

Peristiwady, T. 2006. Ikan-Ikan Laut Ekonomis Penting di Indonesia: Petunjuk Identifikasi. LIPI Press. Jakarta. 270 hal.

[PUSDATIN-KKP] Pusat Data Statistik dan InformasiKementrian Kelautan dan Perikanan. 2013. Buku Statistik 2012 Kelautan dan Perikanan Jakarta. Pusat Data Statistik dan Informasi-Kementrian Kelautan dan Perikanan. 291 hal. 
Saanin, H. 1984. Taksonomi dan Kunci Identifikasi Ikan. Jilid 1 dan 2. Bina Cipta. Jakarta. 508 hal.

Sato, K., H. Inada, Y. Sakamoto, H. Uchida, \& S. Tsuda. 2010. Trial Operation of Led Fishing Light for Squid Jigging. The Energy Use in Fisheries Symposium: Improving Efficiency and Technological Innovations from a Global Perspective. Sheraton Hotel Seattle, Washington. 49 pp.

Sudirman. 2003. Analisis Tingkah Laku Ikan untuk Mewujudkan Teknologi Ramah Lingkungan Dalam Proses Penangkapan pada Bagan Rambo. Disertasi Program Pascasarjana Institut Pertanian Bogor. Bogor. 251 hal. (Tidak diterbitkan).

Sudirman, \& M.N. Nessa. 2011. Perikanan Bagan dan Aspek Pengelolaannya. Universitas Muhammadiyah Malang Press. Malang. 234 hal.
Sulaiman, M. 2006. Pendekatan Akustik Dalam Studi Tingkah Laku Ikan Pada Proses Penangkapan Dengan Alat Bantu Cahaya. Thesis Program Pascasarjana Institut Pertanian Bogor. Bogor. 76 hal. (Tidak diterbitkan).

Toeda H., H. Inada, K. Ozawa, E. Sano, \& T. Watanabe. 2010. Practicable Led Fishing Light for Saury Lift-Net. Information Collection in Energy Efficiency for Fisheries (ICEEF2010). CNRISMAR, Ancona Italy. $189 \mathrm{pp}$.

Trihendradi C. 2012. Step by Step SPSS 20 Analisis Statistik. CV Andi Offset. Yogyakarta. 310 hal.

Yamashita, Y., Y. Matsushita \& T. Azuno. 2012. Catch Performance of Coastal Squid Jigging Boats Using LED Panels in Combination with Metal Halide Lamps. Fish.Res. 113 (1):182-189. 